\title{
Research on Image Quality and Effective dose by Exposure Index Variation
}

\author{
Hyun Soo Kim ${ }^{*}$, Jae Ho Jeong ${ }^{* * * * * * *}$, Jong Woong Lee ${ }^{* * * * * * * *}$ \\ Dept. of Radiological Technology, Shingu College*, Dept. of Radiology, Kyung Hee Medical Center**, \\ Dept. of Radiology, Kyung Hee University Hospital at Gang-dong***, \\ $3 D$ Display Research Center, Dept. of Electronic Engineering, Kwangwoon University****
}

\section{Exposure Index변화에 따른 Image Quality와 Effective dose 에 대한 연구: a Monte Carlo Simulation Study}

\author{
김현수 ${ }^{*}$, 정재호 ${ }^{* * * * * * *}$, 이종웅**,***** \\ 신구대학교 방사선과*, 경희의료원**, 강동경희대병원**, 광운대학교 전자공학과****
}

\begin{abstract}
Comparing with film-screen system, flat-panel detector has extensive dynamic range. Focusing flat-panel detector, whole body human phantom PBU-50 (Kyoto, kagaku, Japan) was used to perform comparative study of the estimate of image quality and exposure dose. the exposure condition was $81 \mathrm{kV}$ and $20 \mathrm{mAs}$, which is used for Abdomen supine exam in clinical area. As a result of the $\mathrm{kV}$ change of the interpreted medical image which has over $30 \mathrm{~dB}$ of PSNR value, the value of DAP shows the difference of 19.6 times. Moreover, the result of comparing $\mathrm{kV}$ change with effective dose of ICRP 103 shows that stochastic effect was increased by over exposure. Therefore, it is significantly necessary that digital radiation technical chart will be used to obtain high quality image and make the standard of dose by educating radio-technologist continually.
\end{abstract}

Key Words : Exposure Index, Dynamic rang, Effective dose, PSNR, Monte Carlo technique

\section{요약}

평판 검출기(flat-panel detector)는 필름-스크린 시스템과 비교하여 넓은 범위의 노출지수(dynamic range)를 갖 게 된다. 평판 검출기를 대상으로 임상에서 일반적으로 사용하고 있는 Abdomen supine 노출 조건인 $81 \mathrm{kV}$ 에 $20 \mathrm{mAs}$ 를 기준으로 전신형 팬텀 whole body human phantom PBU-50 (Kyoto, kagaku, Japan)을 모의 환자로 화질평가와 피폭선량측면에서 비교 연구하였다. PSNR값이 $30 \mathrm{~dB}$ 이상으로 판독 가능한 영상의 $\mathrm{kV}$ 변화에 따른 DAP값은 약 19.6 배 차이를 나타냈다. 또한 $\mathrm{kV}$ 변화에 따른 유효선량을 ICRP 103 을 기준으로 비교한 결과 방사선에 의한 확률적 영향이 증 가함을 알 수 있었다. 방사선검사자의 지속적인 교육 및 지도를 통한 우리나라에 맞는 디지털 방사선 Technical chart 를 마련하여 양질의 영상과 환자피폭선량에 대한 기준 선량을 마련해야 할 것이다.

중심단어: 노출지수, 역동범위, 유효선량, PSNR, 몬테카를로 시뮬레이션 


\section{I. 서론}

우리에게 노출되는 전체 방사선 중 자연방사선은 약 $85 \%$ 정도이다. 나머지 대부분은 X-ray 검사 등 의료 방사선에 의해 피폭되어 지고 있다. 의료기관에서 방 사선을 이용한 영상의학 검사는 행위에 대한 정당성 을 확보하여 의료분야에 사용하고 있다. 또한 국제방 사선방어위원회(ICRP:International Commission on Radiological Protection)에서 권고하는 ALARA (As Low As Reasonably Achievable) 개념에 따라 최적의 영상을 얻으면서 환자가 받는 선량을 최소화 하도록 권고하 고 있다. ${ }^{[1]}$ 환자가 받는 방사선량은 검사부위 및 의료 기관, 국가마다 차이가 있으며, UN방사선영향과학위 원회(UNSCEAR:United Nations Scientific Committee on the Effects of Atomic Radiation) 2000 보고서에 따르면 유럽연합(EC)이나 $\mathrm{OECD}$ 국가의 경우 동일한 영상의 학 검사를 받았다 하더라도 환자가 받는 선량은 의료 기관에 따라 $10 \sim 20$ 배의 큰 차이를 나타내고 있다. ${ }^{[2]}$ 동일 검사에 대해 의료기관에 따른 선량의 차이는 아 날로그 방사선장비에 비해 넓은 노출지수 때문에 가 능하다. 또한 평판 검출기(flat-panel detector)의 넓은 노 출지수 는 bone과 soft tissue와 같이 physical contrast가 차가 큰 조직도 한 화면에 표시할 수 있는 장점이 있 다 ${ }^{[3]}$. 평판 검출기는 104 단계의 grayscale을 가지고 인간 눈과 비슷한 노출지수를 가지는 필름-스크린 시스템은 대략 101.5 단계의 grayscale을 가진다. 따라서 평판 검출 기는 필름-스크린 시스템에 비교하여 넓은 범위의 영 상 노출 허용도를 갖게 된다. 즉 평판 검출기의 폭넓 은 노출지수로 인하여 영상의 화질 저하 없이 과소피 폭이나 과다피폭이 발생할 수 있다. 이는 window level 과 window width의 조절을 통해 전체의 노출지수 중에 인간의 눈이 인식 가능한 부분을 시각화 할 수 있기 때문이다. 이러한 평판 검출기의 장점인 폭넓은 노출 지수는 직관적으로 보이는 영상을 양질로 유지하고자 하는 욕구에 의해 필요 이상 높은 피폭을 유지하려는 현상이 발생하게 된다. 디지털 방사선 영상은 진단 성 능의 어떠한 감소도 없이 $30 ~ 50 \%$ 의 선량 감소를 이룰 수 있지만 이러한 dose creep현상에 의해 필름/스크린 시스템에 비해 상대적으로 환자 피폭선량은 줄어들고 있지 않다 ${ }^{[4]}$. 평판 검출기의 디지털 영상은 필름/스크
린 시스템과 달리 넓은 노출지수로 인하여 시각적으 로 피폭 선량의 과소를 평가하기 어렵기 때문이다. 본 연구에서는 평판 검출기를 대상으로 피폭선량에 따른 정량적인 화질평가를 위해 Image J를 이용하여 방사선 선량에 따른 영상의 PSNR을 비교 연구하였다. 일반적 으로 PSNR이 $30 \mathrm{~dB}$ 이상이면 임상적으로 영상의 질적 차이를 구분할 수 없고, PSNR이 높을수록 영상의 질 이 좋게 평가 된다 ${ }^{[5]}$. 평판 검출기에 있어 PSNR을 기 준으로 $30 \mathrm{~dB}$ 이상인 영상을 기준으로 $\mathrm{EI}($ Exposure Index)와 DAP값을 도출하였다. 피폭 선량 측면은 $\mathrm{PSNR}$ 값이 $30 \mathrm{~dB}$ 이상인 화질의 엑스선 선질 변화를 SRS-78 프로그램으로 시뮬레이션하고 선행실험에서 도출된 DAP(Dose Area Product)를 조사하여 PCXMC 2.0 Monte Carlo 전산모사를 통하여 유효선량을 시뮬레 이션 하고 risk factor를 비교하고 평가하여 판독 가능 한 최적의 검사조건을 도출해 보고자 한다.

\section{II. 실험 및 방법}

\section{Digital Imaging System and acquisition}

본 연구를 진행하기 위해서 간접변환방식의 비정질 실리콘(a-Si)을 기반으로 한 디지털 X-선 발생장치 (DIGITAL DIAGNOST VR, Philips, Netherland)를 사용 하였다. Table 1은 X-ray tube assembly와 detector의 기 본 특성을 조사한 것이다.

Table 1. Principal characteristics of Digital Radiography System

\begin{tabular}{cc}
\hline DETECTOR & Trixell \\
\hline Detection type & Indirect \\
\hline X-Ray Conversion & Cesium Iodide Scint il lator \\
\hline Receptor Type & Amor phous Sil icon \\
\hline Panel Act ive Size & $43 \times 43 \mathrm{~cm}$ \\
\hline Pixel Pitch & $143 \mathrm{Micron}$ \\
\hline Active Pixel Matr ix & $3,001 \times 3,001$ \\
\hline Bit Processing & $14 \mathrm{bits}$ \\
\hline Limiting Resolution & $3.5 \mathrm{LP} / \mathrm{mm}$ \\
\hline Dose range & $400 \sim 800$ \\
\hline Detector Cool ing & Air \\
\hline Anode heat capacity & $300,000 \mathrm{HU}$ \\
\hline Focal Spots & $0.6 / 1.2 \mathrm{~mm}$ \\
\hline Anode angle & $13^{\circ}$ \\
\hline Normal Vol tage & $150 \mathrm{kV}$ \\
\hline Permanent fil ter (mmAl) & 2.5 \\
\hline
\end{tabular}


$\mathrm{X}$-선 발생장치의 고유여과는 $2.5 \mathrm{mmAl}$ 이며 added filter는 사용하지 않았다. '진단용방사선발생장치의 안 전관리에 관한 규칙'의 검사기준을 통과한 장비를 사 용하여 실험결과에 대한 객관성을 확보였다 ${ }^{[6]}$.

조직등가물질로 이루어진 일반 촬영용 전신형 팬텀 whole body human phantom PBU-50 (Kyoto, kagaku, Japan)을 모의 환자로 실험하였다.

첫 번째 실험 조건은 Abdomen supine 검사 조건인 $81 \mathrm{kV}$ 를 기준으로 $\mathrm{mAs}$ 를 고정하고 $\mathrm{kV}$ 값을 24 단계의 변화에 따라 실험하였고, 두 번째 실험 조건은 $\mathrm{kV}$ 를 고정하고 $\mathrm{mAs}$ 값을 25 단계 변화를 주고 실험하였다.

실험영상의 DICOM header 정보에서 $\mathrm{EI}$ 와 $\mathrm{DAP}$ 를 측정하였다.

\section{Image quality}

$\mathrm{EI}$ 변화에 따른 영상의 화질 평가를 하기 위해 DICOM image processing software (Image J Version 1.43u; National Institutes of Health, Bethesda, MD, USA) 를 이용하였다.

임상에서 사용하고 있는 검사 조건을 기준으로 실 험 조건에 대한 화질의 차이를 정량적으로 측정 가능 한 $\operatorname{SNR}($ Signal to Noise Ratio), PSNR(Peak Signal to Noise Ratio), RMSE(Root Mean Square Error), $\mathrm{MAE}($ Mean Absolute Error)등을 측정하여 결과값을 비 교하였다 ${ }^{[7][8]}$.

\section{Source of Spectrum to be Processed}

Photon energy spectrum은 보통 연속 X-선과 특성 X선으로 나타난다. 특성 $\mathrm{X}$-선은 전자 궤도간의 에너지 차에 관계되는 것으로, 그 파장은 표적으로 사용된 원 소에 따라 고유하며 X-선관에 걸어준 전압과는 관계 없다.

$\mathrm{kV}$ 변화에 따라 photon energy spectrum의 가로축인 에너지는 변화하지 않고 $\mathrm{X}$-선의 선량만 변화하게 된 다.

$\mathrm{kV}$ 변화에 따른 광자의 fluence 변화를 simulation 하 기 위해 SRS-78 프로그램에 입력하여 하였다. Fig 1.

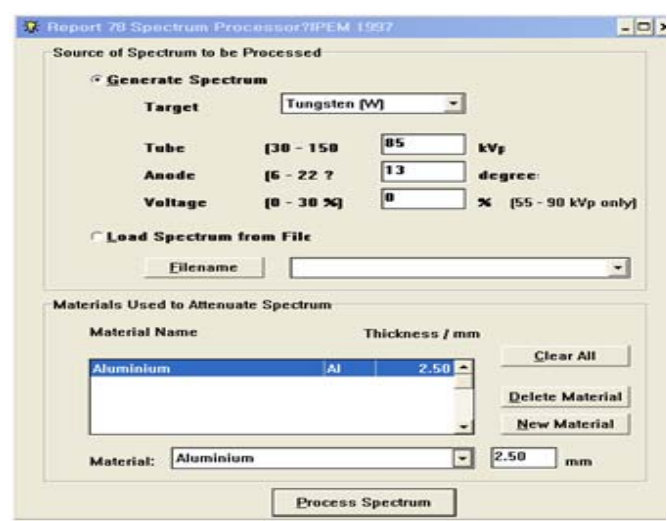

Fig 1. Photon Energy simulation by using SRS-78

\section{Effective dose}

노출지수 변화에 따른 환자의 organ dose와 effective dose, risk factor를 계산하기 위하여 DICOM header정보 에서 측정한 $\mathrm{DAP}$ 값을 $\mathrm{PCXMC}$ Dose Calculations Version 2.0.1(PCXMC, STUK, Helsinki, Finland)프로그램 에 입력하였다. Fig 2.

$\mathrm{PCXMC}$ 프로그램은 다양한 검사조건에 따른 소아와 성인phantom을 이용하여 방사선 조사로 인한 phantom 의 유효 선량과 organ dose, risk factor를 ICRP 103(2007) 버전과 ICRP 60(1991)버전의 tissue 가중인자를 사용하 여 simulation하는 Monte Carlo프로그램이다.

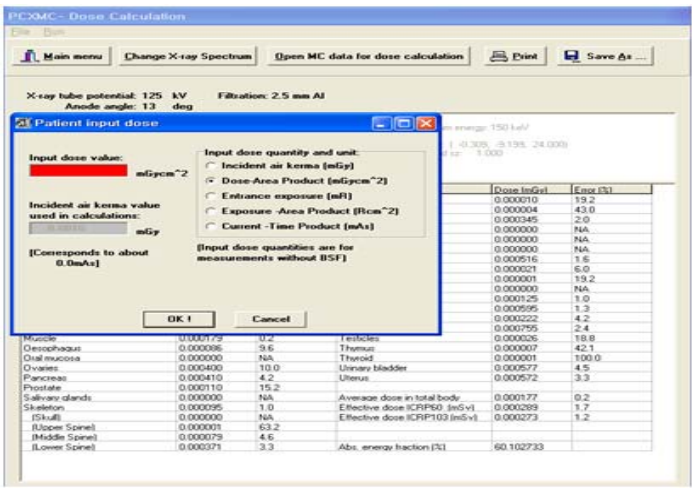

Fig 2. Effective dose calculation by Monte Carlo simulation

\section{III. 결과}

본 연구에서 Exsposure Index변화에 따른 DAP값을 측정하기 위해 $\mathrm{kV}$ 고정 실험과 $\mathrm{mAs}$ 고정 실험 영상의 
"Research on Image Quality and Effective dose by Exposure Index Variation"

DICOM header를 분석하였다.

첫 번째 검사조건변화에 따른 $\mathrm{DAP}$ 과 $\mathrm{EI}$ 값은 임상 에서 일반적으로 사용하고 있는 Abdomen supine 노출 조건인 $81 \mathrm{kV}$ 에 $20 \mathrm{mAs}$ 를 기준으로 실험하였다. $81 \mathrm{kV}$ 에 $20 \mathrm{mAs}$ 의 DAP값은 $1918.5 \mathrm{mGycm} 2$ 로 나타났으며 $\mathrm{kV}$ 와 $\mathrm{mAs}$ 증가에 따라 $\mathrm{DAP}$ 값은 증가하고 $\mathrm{EI}$ 값은 감소하였 고 $\mathrm{kV}$ 와 $\mathrm{mAs}$ 감소에 따라 $\mathrm{DAP}$ 값은 감소하고 $\mathrm{EI}$ 값은 증가하였다. (Table 2, Table3 )

Table 2. Dose Area Product, EI, SNR(dB), PSNR(dB), RMSE and MAE by $k V$ change

\begin{tabular}{|c|c|c|c|c|c|c|}
\hline $\mathrm{kV}$ & $\begin{array}{c}\text { DAP } \\
(\text { (mGycm2) }\end{array}$ & El & $\begin{array}{l}\text { SNR } \\
\text { (dB) }\end{array}$ & $\begin{array}{l}\text { PSNR } \\
(d B)\end{array}$ & RMSE & MAE \\
\hline 125 & 4460.6 & 40 & 12.056 & 19.115 & 453.423 & 414.610 \\
\hline 117 & 3957.0 & 50 & 14.860 & 21.919 & 328.309 & 299.552 \\
\hline 109 & 3465.4 & 63 & 16.808 & 23.868 & 262.344 & 239.585 \\
\hline 102 & 3048.5 & 80 & 19.434 & 26.493 & 193.902 & 174.805 \\
\hline 96 & 2708.6 & 100 & 23.178 & 30.237 & 126.006 & 110.864 \\
\hline 90 & 2377.6 & 125 & 27.157 & 34.216 & 79.699 & 67.221 \\
\hline 85 & 2124.0 & 160 & 28.477 & 35.536 & 68.460 & 52.763 \\
\hline 81 & 1918.5 & 200 & $\infty$ & $\infty$ & 0 & 0 \\
\hline 77 & 1731.9 & 250 & 28.730 & 35.789 & 66.494 & 55.693 \\
\hline 73 & 1549.6 & 320 & 26.378 & 33.438 & 87.172 & 74.529 \\
\hline 70 & 1413.5 & 400 & 25.042 & 32. 102 & 101.666 & 87.425 \\
\hline 66 & 1249.5 & 500 & 23.890 & 30.949 & 116.090 & 100.166 \\
\hline 63 & 1125.8 & 500 & 23. 192 & 30.252 & 125.799 & 108.543 \\
\hline 60 & 1002.8 & 630 & २2.091 & 29.150 & 142.803 & 124.361 \\
\hline 57 & 891.9 & 800 & 21.608 & 28.667 & 150.975 & 130.368 \\
\hline 55 & 817.4 & 1000 & 20.984 & 28.043 & 162.217 & 140.018 \\
\hline 52 & 707.0 & 1250 & 20.083 & 27.142 & 179.951 & 154.370 \\
\hline 50 & 633.0 & 1600 & 19.417 & 26.476 & 194.293 & 165.599 \\
\hline 48 & 569.7 & 2000 & 18.617 & 25.676 & 213.038 & 180.475 \\
\hline 46 & 505.8 & 2000 & 15.896 & २2.955 & 291.401 & 245.724 \\
\hline 44 & 442.3 & 2500 & 15.567 & २2.6२6 & 302.647 & 252.656 \\
\hline 42 & 378.9 & 3200 & 15.547 & २2.606 & 303.356 & 249.981 \\
\hline 41 & 347.1 & 4000 & 15.395 & २2.455 & 308.691 & 252.655 \\
\hline 40 & 315.8 & 4000 & 15.675 & 22.734 & 298.919 & 242.200 \\
\hline
\end{tabular}

Table 3. Dose Area Product, EI, SNR(dB), PSNR(dB), RMSE and MAE by MAs change

\begin{tabular}{ccccccc}
\hline $\mathrm{mAs}$ & $\begin{array}{c}\text { DAP } \\
\left.(\mathrm{mGycm})^{2}\right)\end{array}$ & $\mathrm{El}$ & $\begin{array}{c}\text { SNR } \\
(\mathrm{dB})\end{array}$ & $\begin{array}{c}\text { PSNR } \\
(\mathrm{dB})\end{array}$ & RMSE & MAE \\
\hline 127 & 11984.6 & 32 & 8.564 & 15.586 & 680.733 & 594.175 \\
\hline 100 & 9588.6 & 40 & 10.495 & 17.517 & 545.015 & 482.841 \\
\hline 81 & 7671.1 & 50 & 12.366 & 19.388 & 439.415 & 388.14 \\
\hline 64 & 6041.2 & 63 & 14.687 & 21.708 & 336.384 & 295.516 \\
\hline 51 & 4794.8 & 80 & 17.301 & 24.323 & 248.945 & 217.566 \\
\hline 40 & 3837.0 & 100 & 20.274 & 27.296 & 176.79 & 153.652
\end{tabular}

\begin{tabular}{ccccccc}
\hline 32 & 3070.0 & 125 & 23.827 & 30.849 & 117.44 & 102.413 \\
\hline 25 & 2398.8 & 160 & 27.483 & 34.505 & 77.091 & 64.262 \\
\hline 20 & 1919.4 & 200 & $\infty$ & $\infty$ & 0 & 0 \\
\hline
\end{tabular}

$\begin{array}{lllllll}16 & 1535.9 & 250 & 28.8 & 35.822 & 66.244 & 54.98\end{array}$

\begin{tabular}{lllllll}
12 & 1199.4 & 320 & 26.919 & 33.941 & 82.263 & 69.768 \\
\hline
\end{tabular}

\begin{tabular}{lllllll}
\hline 10 & 959.7 & 400 & 25.612 & 32.634 & 95.62 & 80.899 \\
\hline
\end{tabular}

$\begin{array}{lllllll}8 & 768.9 & 500 & 24.839 & 31.86 & 104.53 & 88.4\end{array}$

\begin{tabular}{lllllll}
\hline 6 & 606.9 & 630 & 24.756 & 31.778 & 105.522 & 88.159 \\
\hline 5 & 480.3 & 800 & 24.588 & 31.61 & 107.583 & 89.875 \\
\hline 4 & 384.5 & 1000 & 24.289 & 31.311 & 111.357 & 93.841 \\
\hline
\end{tabular}

$\begin{array}{lllllll}3 & 306.8 & 1250 & 24.14 & 31.162 & 113.283 & 95.676\end{array}$

\begin{tabular}{lllllll}
\hline 2 & 240.7 & 2000 & 23.932 & 30.954 & 116.024 & 97.85 \\
\hline
\end{tabular}

$\begin{array}{lllllll}2 & 194.6 & 2500 & 23.516 & 30.537 & 121.727 & 102.776\end{array}$

\begin{tabular}{lllllll}
\hline 1 & 156.6 & 3200 & 23.272 & 30.294 & 125.184 & 105.818 \\
\hline 1 & 122.7 & 4000 & 22.613 & 29.635 & 135.054 & 113.62 \\
\hline 1 & 96.8 & 6300 & 22.001 & 29.023 & 144.91 & 121.461 \\
\hline 1 & 75.7 & 8000 & 20.421 & 27.442 & 173.834 & 141.698 \\
\hline 1 & 57.5 & 8000 & 20.183 & 27.205 & 178.658 & 145.629 \\
\hline 1 & 45.1 & 8000 & 18.945 & 25.967 & 206.016 & 164.49
\end{tabular}



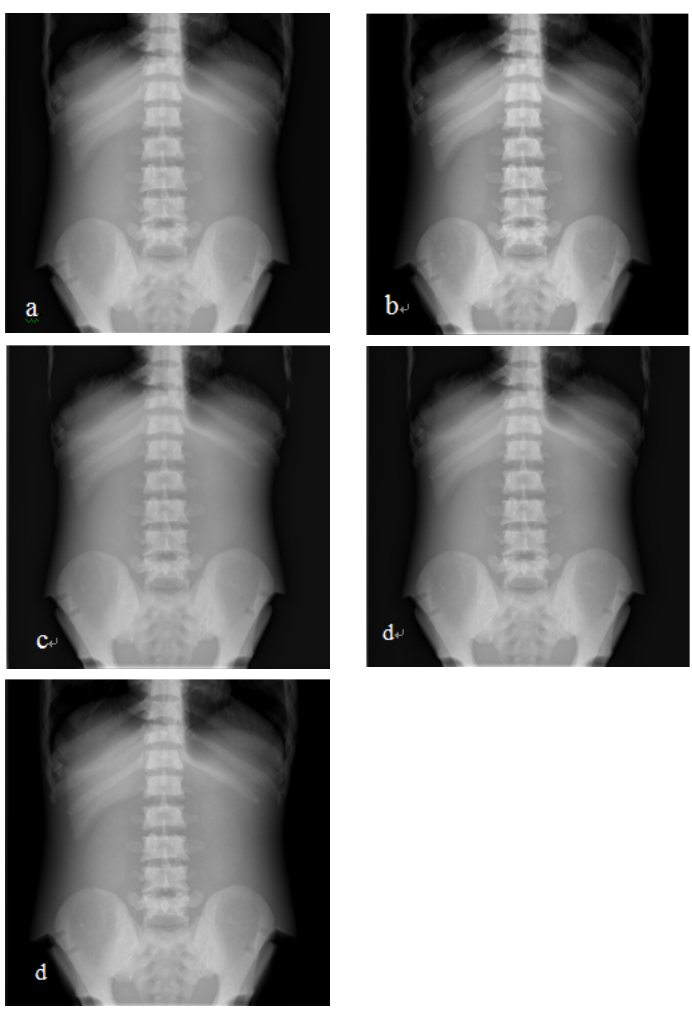

Fig. 3 a. $96 \mathrm{kV} 20 \mathrm{mAs}$ and PSNR is $30.237 \mathrm{~dB}$, b. $81 \mathrm{kV}$ $20 \mathrm{mAs}$ and PSNR is $\infty \mathrm{dB}$, c. $63 \mathrm{kV} 20 \mathrm{mAs}$ and PSNR is $30.252 \mathrm{~dB}$, d. $81 \mathrm{kV} 32 \mathrm{mAs}$ and PSNR is $30.849 \mathrm{~dB}$, e. $81 \mathrm{kV}$ $1 \mathrm{mAs}$ and PSNR is $30.294 \mathrm{~dB}$

두 번째 $81 \mathrm{kV}$ 에 $20 \mathrm{mAs}$ 의 Abdomen supine 영상을 reference로 하여 $\mathrm{kV}$ 변화에 따른 Image quality를 비교하 기 위하여 $\operatorname{SNR}(\mathrm{dB}), \operatorname{PSNR}(\mathrm{dB}), \mathrm{RMSE}, \mathrm{MAE}$ 수치를 비 교하였다. $\mathrm{SNR}(\mathrm{dB})$ 은 reference영상을 기준으로 $\mathrm{kV}$ 와 $\mathrm{mAs}$ 변화에 따라 감소하였고 RMSE와 MAE값은 증가 하였다. $\mathrm{kV}$ 조건 변화에 따른 $\operatorname{PSNR}(\mathrm{dB})$ 값은 $63 \mathrm{kV}$ 에서 $96 \mathrm{kV}$ 까지만 $30 \mathrm{~dB}$ 이상으로 측정되었고 $\mathrm{mAs}$ 조건 변 화에 따른 $\operatorname{PSNR}(\mathrm{dB})$ 값은 $1 \mathrm{mAs}$ 에서 $32 \mathrm{mAs}$ 까지 $30 \mathrm{~dB}$ 이상으로 측정되어 육안으로 Image Quality의 변화를 알 수 없었다.fig 3 .

즉 Image Quality의 저하 없는 $\mathrm{kV}$ 와 $\mathrm{mAs}$ 의 변화에 따른 $\mathrm{DAP}$ 값은 $\mathrm{mAs}$ 를 고정하였을 경우 $96 \mathrm{kV}$ 에서 $2708.6 \mathrm{mGycm} 2,63 \mathrm{kV}$ 에서 $1125.8 \mathrm{mGycm} 2$ 로 약 2.4배 의 차이가 있었으며 $\mathrm{kV}$ 를 고정하였을 경우 $32 \mathrm{mAs}$ 에서 $3070.0 \mathrm{mGycm} 2,1 \mathrm{mAs}$ 에서 $156.6 \mathrm{mGycm} 2$ 로 약 19.6 배의 차이가 있었다.
Fig 4.은 $\mathrm{kV}$ 변화에 따른 photon energy spectrum 의 변화를 나타낸다.
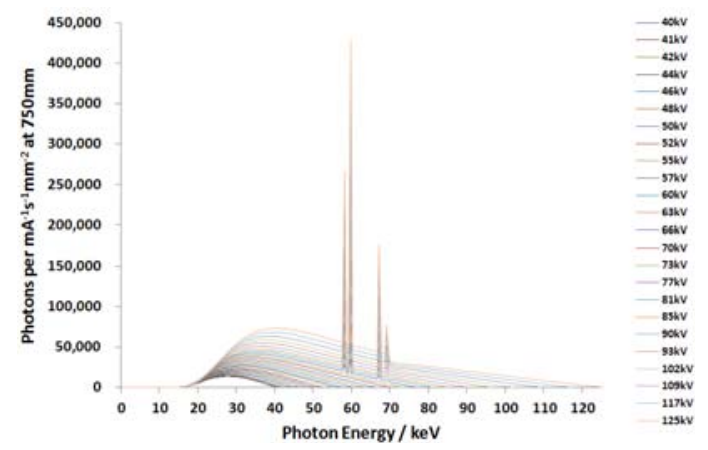

Fig 4. Calculated photon spectra: $40 \mathrm{kV}$ from the $125 \mathrm{kV}$

$\mathrm{kV}$ 증가에 따라 연속 $\mathrm{X}$ 선이 Tube에 부여된 관전압 의 범위에서 분포하고 $59 \mathrm{keV}$ 부근에서 $\mathrm{L}$ 각 전자의 특성 $\mathrm{X}$-ray가 발생하고 $70 \mathrm{keV}$ 에서 $\mathrm{K}$ 각 전자의 특성 $\mathrm{X}$-ray가 발생하고 있다. Table 5.는 Image Quality의 저하가 없는 $\mathrm{kV}$ 에 따른 Photon energy의 특성을 나타낸다.

Table 4. Analysis of processed spectrum

\begin{tabular}{cccc}
\hline kV & $\begin{array}{c}\text { Mean Photon } \\
\text { Energy (keV) }\end{array}$ & $\begin{array}{c}\text { Air Kerma } \\
\text { (Gy /mAs at 750mm) }\end{array}$ & $\begin{array}{c}\text { 1stHVL } \\
\text { (mmAl) }\end{array}$ \\
\hline 96 & 48.5 & 224 & 3.485 \\
\hline 90 & 46.6 & 201.9 & 3.235 \\
\hline 85 & 45 & 183.9 & 3.029 \\
\hline 81 & 43.6 & 169.8 & 2.868 \\
\hline 77 & 42.1 & 155.9 & 2.71 \\
\hline 73 & 40.6 & 142.4 & 2.558 \\
\hline 70 & 39.5 & 132.5 & 2.449 \\
\hline 66 & 38.1 & 119.8 & 2.311 \\
\hline 63 & 37.1 & 110.3 & 2.208 \\
\hline
\end{tabular}

Photon energy의 평균값은 $96 \mathrm{kV}$ 에서 $48.5 \mathrm{keV}, 81 \mathrm{kV}$ 에 서 $43.6 \mathrm{keV}, 63 \mathrm{kV}$ 에서 $37.1 \mathrm{keV}$ 로 나타났다. 공기 중에 부 여하는 운동에너지의 합인 air kerma값은 $96 \mathrm{kV}$ 에서 224 , $81 \mathrm{kV}$ 에서 $169.8,63 \mathrm{kV}$ 에서 110.3 으로 나타나 약 2 배의 차 이를 나타냈다. $\mathrm{kV}$ 에 따른 $1 \mathrm{stHVL}$ 은 $96 \mathrm{kV}$ 에서 $3.485 \mathrm{mmAl}, 81 \mathrm{kV}$ 에서 $2.868 \mathrm{mmAl}, 63 \mathrm{kV}$ 에서 $2.208 \mathrm{mmAl}$ 으로 나타나 약 1.57 배의 선질의 차이를 나타냈다.

Table 5는 Image Quality의 저하가 없는 $\mathrm{kV}$ 의 DAP값 을 PCXMC에 입력하여 Monte Carlo simulation에 의해 유효선량을 나타낸다. 
"Research on Image Quality and Effective dose by Exposure Index Variation"

Table 5. A comparison of the Effective dose by $\mathrm{kV}$ change.

\begin{tabular}{ccc}
\hline $\mathrm{kV}$ & $\begin{array}{c}\text { Effective dose } \\
\text { ICRP60 (mSv) }\end{array}$ & $\begin{array}{c}\text { Effective dose } \\
\text { ICRP103 (mSv) }\end{array}$ \\
\hline 96 & 0.736269 & 0.698703 \\
\hline 90 & 0.646284 & 0.61331 \\
\hline 85 & 0.577363 & 0.547905 \\
\hline 81 & 0.521497 & 0.494889 \\
\hline 77 & 0.470777 & 0.446757 \\
\hline 73 & 0.421213 & 0.399722 \\
\hline 70 & 0.384225 & 0.364621 \\
\hline 66 & 0.339646 & 0.30052 \\
\hline 63 & 0.30052 & 0.285187 \\
\hline
\end{tabular}

ICRP60에서 $63 \mathrm{kV}$ 에서는 유효선량이 $0.30052 \mathrm{mSv}$, $81 \mathrm{kV}$ 에서는 $0.521497 \mathrm{mSv}, 96 \mathrm{kV}$ 에서는 $0.736269 \mathrm{mSv}$ 로 나타나 약 2.5 배의 유효선량차이가 있었다. ICRP103에 서도 $63 \mathrm{kV}$ 에서는 유효선량이 $0.285187 \mathrm{mSv}, 81 \mathrm{kV}$ 에서 는 $0.494889 \mathrm{mSv}, 96 \mathrm{kV}$ 에서는 $0.698703 \mathrm{mSv}$ 로 나타나 약 2.5 배의 유효선량 차이가 있었다.fig 5.

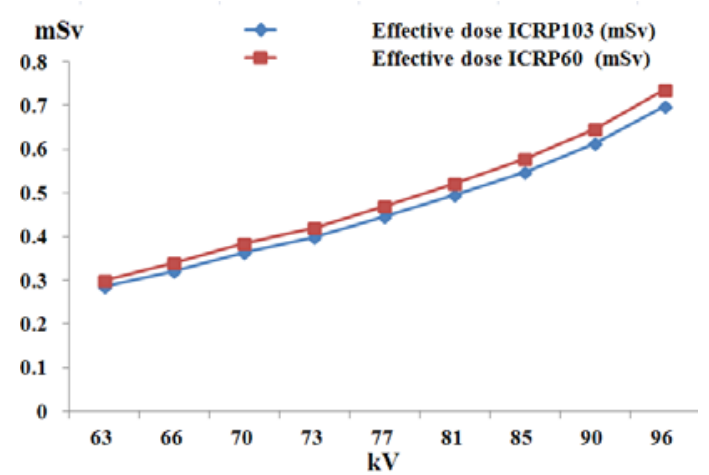

Fig 5. Effective dose by kV change

Fig 6.의 risk of exposure-induced death(REID) for various cancer는 Image Quality의 저하가 없는 $\mathrm{kV}$ 선택에 따른 결정적 영향이 아닌 확률적 영향의 복부 부분 risk factor를 나타낸다.

조사야 내의 장기 중 조직가중치가 가장 높은 stomach cancer의 발병확률이 가장 높았으며 $\mathrm{kV}$ 선질 의 감소에 따라 cancer발병 확률도 떨어졌다.

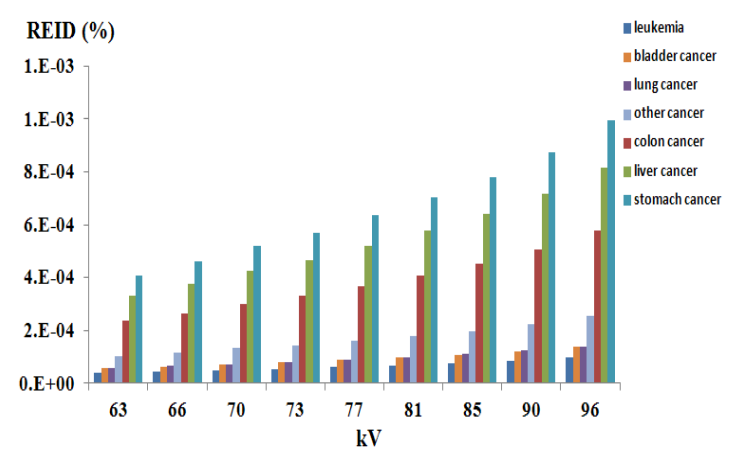

Fig 6. Risk of exposure-induced death(REID) for various kV

\section{III. 고찰}

디지털 방사선 장비는 아날로그 방식과 달리 넓은 노출지수를 갖는다. 노출지수가 넓다는 것은 bit depth 가 넓다는 것이고 필름과 비교하여 검사조건에 대해 $\mathrm{kV}$ 선택이 넓다는 것을 의미한다. Film/screen방식은 speed가 $100 \sim 400$ 정도로 사람의 눈의 농도 구분 단계 인 약 101.5 의 dynamic rang에 맞춰 검사하였다. 디지털 방사선과 비교하여 상대적으로 좁은 dynamic rang로 인하여 환자에게 1010 인 넓은 노출지수를 갖는 디지털 방사선 보다 검사조건 선택의 폭이 좁았다. 디지털 방 사선은 under exposure와 over exposure 상에서도 판독 가능한 Image quality를 나타낼 수 있다. 따라서 디지털 방사선은 검사자가 직관적으로 환자에게 피폭되는 선 량에 대해 쉽게 알 수 없다. 영국 자료에 따르면 Film/screen 방식에서도 같은 검사라도 병원에 따라 약 71 배의 환자선량의 차이가 있었다 ${ }^{[9]}$.

디지털 방사선에서는 넓은 노출지수로 인해 더 많 은 환자선량의 차이가 발생한다. 노출지수에 따른 유 효선량값에서도 적정한 quality의 Image를 기준으로 약 4 배 이상의 차이가 나타났다. 본 연구에서 유효선량은 $0.285187 \mathrm{mSv}$ 에서 $0.698703 \mathrm{mSv}$ 까지 적은 양으로 나타 났지만 동일 부위의 다른 검사와 반복적인 검사로 인 하여 확률적 영향은 증가한다. 또한 성장기 어린이의 경우 방사선 감수성이 높고 남아있는 여생이 길며, 여 러 차례 검사할 가능성이 높기 때문에 적은 양의 방사 선도 암 발생 확률을 높이는 요인으로 작용하므로 가 능하면 방사선 선량에 대해 최적화 하려는 노력이 필 요하다 ${ }^{[10]}$. 적정한 Image quality에 대해 EI의 변화는 환 
"Journal of the Korean Society of Radiology, Volume 7, Number 1"

자피폭량의 간접적인 지표로서 이용되며 적정 $\mathrm{EI}$ 는 200-800이 적정하다 ${ }^{[11]} .81 \mathrm{kV}$ 를 기준으로 PSNR값이 $30 \mathrm{~dB}$ 이상인 EI값은 100-500사이로 나타나 ICRP 권고 에 따라 유효선량을 약 2.5 배 가량 최적화 할 수 있으 며 조사야 내의 Risk factor또한 최적화 할 수 있다. ICRP 60 과 ICRP 103의 유효선량의 감소비율의 차이점 은 생물학적인 조직 가중치의 변화로 나타났다.

본 연구는 디지털 방사선 환경에서 선량감소에 따 른 화질 저하 없이 넓은 노출지수를 이용하여 양질의 image quality를 유지할 수 있음을 확인 하였다.

\section{III. 결론}

디지털 방사선환경에서 영상의 화질과 피폭선량은 비례관계이다. 디지털 방사선 장비의 넓은 노출지수는 적은 선량으로 영상의 화질저하 없이 검사가 가능하 다. 그러나 operating factor중에 하나인 $\mathrm{kV}$ 와 $\mathrm{mAs}$ 의 변 화 따라 영상의 화질과 피폭선량에 대해 검증한 것과 같이 계속적인 연구를 통해 필요이상의 선량을 사용 하여 검사하는 병원에 대해 지속적인 교육 및 지도를 통해 개선해 나갈 필요성이 있다. 또한 우리나라에 현 실에 맞는 디지털 방사선 Technical chart를 마련하여 양질의 영상과 환자피폭선량에 대한 기준선량을 마련 해야 할 것이다.

\section{참고문헌}

[1] ICRP: 1990 Recommendations of the International Commission on RadiologicalProtection. Publication 60, Annals of the ICRP Vol. 21, No. 1-3, Pergamon Press,Oxford(1991)

[2] UNSCEAR 2000 Report Vol. I Source and Effects of Ionization Radiation, AnnexD Medical Radiation Exposure, UNSCEAR(2000)

[3] Korner, M., et al. Advances in digital radiography: physical principles and system overview.Radiographics, Vol. 27, No. 3, pp. $675-686,2007$.

[4] Williams, M. B., et al. Digital radiography image quality: image acquisition. JAmCollRadiol, Vol. 4. No. 6, pp.371-388,2007

[5] Hyunsoo, Kim. et al. Picture Quality According to the Type of Detector in Full-field Digital Mammography. Journal of the Korean Physical Society.Vo. 58, No 2, pp.364-371.2011

[6]「진단용방사선발생장치의 안전관리에 관한 규칙」
보건복지가족부령 제 156호. (2010.01.22 개정).

[7] Y. HASHIMOTO, S. SAMPEI, N. MORINAGA. Channel Monitor-based Unequal Error Protection with Dynamic OFDM Subcarrier Assignment for Video Transmission. In Proceedings of 2002 IEEE Vehicular Technology Conference, Fall 2002.

[8] Ung Keun Cho, Jin Hyuk Hong, Sung Bae Cho, Image enhancement based on the Genetic Algorithm for reducing impulsive noises. Vol. 33, No. 1(B), 2006.

[9] NRPB R200 : Anational survey of dose to patients undergoing a selection of routine X-ray examination in English hospitals.National Radiological Protection Board,England, 1986.

[10] Brenner DJ, Hall EJ. Computed tomography: an increasing source of radiation exposure. N Engl J Med Vol. 357, pp.22772284, 2007.

[11] Shepard, S. J., et al., An exposure indicator for digital radiography: AAPM Task Group 116 (executive summary), Medical physics. Vol 36, No. 7, pp.2898-2914, 2009. 